on-line at: www.actabp.pl

Regular paper

\title{
Changes in phosphorylation of histone H2A.X and p53 in response of peripheral blood lymphocytes to gamma irradiation
}

\author{
Zdeňka Vilasová1, Martina Řezáčová2®, Jiřina Vávrová1, Aleš Tichý1, Doris Vokurková \\ Friedo Zoelzer ${ }^{3}$, Zuzana Řeháková ${ }^{1}$, Jan Osterreicher ${ }^{1}$ and Emilie Lukášováa \\ ${ }^{1}$ University of Defence, Faculty of Military Health Sciences, Department of Radiobiology, Hradec Králové, Czech \\ Republic; ${ }^{2}$ Charles University in Prague, Faculty of Medicine in Hradec Králové, Department of Biochemistry, \\ Hradec Králové, Czech Republic; ${ }^{3}$ South Bohemian University, Department of Radiology and Toxicology, České \\ Budějovice, Czech Republic; ${ }^{4}$ Czech Academy of Sciences, Institute of Biophysics, Brno, Czech Republic
}

Received: 08 January, 2008; revised: 27 May, 2008; accepted: 12 June, 2008

available on-line: 15 June, 2008

\begin{abstract}
The main aim of this study was to compare the reaction of quiescent and proliferating, i.e. phytohemagglutinin (PHA)-stimulated, human peripheral blood mononuclear cells (PBMCs) to $\gamma$-radiation, and analyse changes of proteins related to repair of DNA damage and apoptosis, such as $\gamma$ H2A.X, p53, p53 phosphorylation at serines-15 and -392, and p21 and their dose dependence. Freshly isolated PBMCs in peripheral blood are predominantly quiescent, in $G_{0}$ phase, and with very low amounts of proteins p53 and p21. Using confocal microscopy we detected dose dependent (0.5-5 Gy) induction of foci containing $\gamma \mathrm{H} 2 \mathrm{~A} . \mathrm{X}(1 \mathrm{~h}$ after $\gamma$-ray exposure), which are formed around radiation-induced double strand breaks of DNA. Apoptosis was detected from $24 \mathrm{~h}$ after irradiation by the dose of $4 \mathrm{~Gy}$ onwards by Annexin V binding and lamin B cleavage. Seventy two hours after irradiation $70 \%$ of $\mathrm{CD}^{+}$lymphocytes were $\mathrm{A}^{+}$. Neither increase in p53 nor its phosphorylation on serine-392 after irradiation was detected in these cells. However, massive increase in p21 (cyclin-dependent kinase inhibitor 1A) was detected after irradiation, which can be responsible for late occurrence of apoptosis in these quiescent cells. PHA-stimulation itself (72 h) caused an increase in early apoptosis $\left(\mathrm{A}^{+} \mathrm{PI}\right)$ in comparison to non-stimulated $\mathrm{PBMCs}\left(38 \% \mathrm{~A}^{+}\right.$ resp. 13.4\%). After PHA-stimulation also the amount of $\gamma \mathrm{H} 2 \mathrm{~A} . \mathrm{X}, \mathrm{p} 53$, and p21 increased, but no phosphorylation of p53 on serine-392 or -15 was detected. Reaction to $\gamma$-radiation was different in PHA-stimulated lymphocytes: the p53 pathway was activated and p53 was phosphorylated on serines-15 and $-3924 \mathrm{~h}$ after irradiation by the dose of $4 \mathrm{~Gy}$. Phosphorylation of p53 at serine-15 increased in a dose-dependent manner in the studied dose range 0.2-7.5 Gy. Also the amount of p21 increased after irradiation. Seventy two hours after irradiation of PHA-stimulated CD3 ${ }^{+} \mathrm{T}^{-}$ lymphocytes by the dose of 4 Gy $65 \%$ of cells were $\mathrm{A}^{+}$.
\end{abstract}

Keywords: lymphocyte, ionizing radiation, p53, phytohemagglutinin (PHA), apoptosis, DNA damage

\section{INTRODUCTION}

In vitro and in vivo irradiation of peripheral blood mononuclear cells (PBMC) by $\gamma$-irradiation induces programmed cell death - apoptosis (Hertveld et al., 1997; Philippé et al., 1997; Cornelissen et al., 2002; Vokurková et al., 2006). This process is time and dose-dependent. It was demonstrated that in
PBMC isolated from blood of healthy donors and irradiated by the dose of 7 Gy apoptosis is not detectable within the first $6 \mathrm{~h}$, but $16 \mathrm{~h}$ after irradiation $50 \%$ of the cells are Annexin $\mathrm{V}$ positive $\left(\mathrm{A}^{+}\right)$, and 48 $\mathrm{h}$ after irradiation almost all cells are $\mathrm{A}^{+}$(Vokurková et al., 2006).

The molecular mechanisms of ionizing radiation (IR)-induced apoptosis in cells of lymphocytic

Corresponding author: Martina Rezacova, Department of Medical Biochemistry, Faculty of Medicine in Hradec Kralove, Simkova 870, 50001 Hradec Kralove, Czech Republic; tel: (420) 4958 16166; fax: (420) 4955 12715; e-mail: rezacovam@lfhk. cuni.cz

Abbreviations: AT, ataxia telangiectasia; ATM, ataxia telangiectasia mutated; A, Annexin V; IR, ionizing radiation; IRIF, ionizing radiation-induced foci; OD, optical density; IOD, integral optical density; NBS, Nijmegen breakage syndrome; PHA, phytohemagglutinin; PBMC, peripheral blood mononuclear cells; PBS, phosphate-buffered saline; TPA, phorbol ester. 
origin were studied in some detail on MOLT-4 cells (T-lymphocytic leukemia) (Szkanderová et al., 2003; 2005; Vávrová et al., 2004). Immediately after DNA DSB damage, histone H2A.X is phosphorylated at serine-139 - $\gamma$ H2A.X (Rogakou et al., 1998; Řezáčová et al., 2008). Bekker-Jensen et al. (2006) described the reaction of U-2-OS cells to IR-induced double strand breaks (DSB) of DNA, during which accumulation of many proteins (53BP1, $\gamma$ H2A.X, phosphorylated ATM kinase, Nbs1) in IR-induced foci (IRIF) was detected. These proteins assemble around DSBs and form optically discernible foci.

One of the initial processes in the response of eukaryotic cells to IR is the activation of ATM kinase (Bakkenist \& Kastan, 2003) by auto-phosphorylation at serine-1981 within minutes after irradiation, which was also detected in MOLT-4 cells (Tichý et al., 2007). The product of the ATM gene plays a pivotal role in sensing DNA damage and consequentially in modulating cell cycle check points. Activated ATM kinase phosphorylates a broad range of substrates related to radiation damage repair and/or apoptosis. One of its substrates is protein p53, which is posttranlationally modified in response to IR, including phosphorylation at serine-15 and -392, within hours after irradiation (Szkanderová et al., 2005). These modifications prevent Mdm2-mediated degradation of p53 and are probably the main reason for the increase in the total amount of p53. Protein p53 acts as a transcriptional factor, which after interaction with DNA activates transcription of other genes, which regulate the cell cycle and apoptosis, including p21, a cyclin-dependent kinase inhibitor (Lakin \& Jackson, 1999). In MOLT-4 cells p21 levels increased $4 \mathrm{~h}$ after irradiation by the dose of 7.5 Gy (Szkanderová et al., 2003). It is generally accepted that p53 is a key molecule responsible for cell cycle arrest in the G1 phase as a response to DNA damage. Human mononuclear cells in peripheral blood are predominantly quiescent, in the $G_{0}$ phase of the cell cycle. Fukao et al. (1999) demonstrated that ATM protein is present at low levels in freshly isolated PBMCs and increases approx. 6- to 10-fold in response to a mitogenic stimulus, reaching a maximum after 3 to 4 days. Increase in ATM in PBMCs is therefore related to proliferation. The increase in ATM protein was accompanied by an increase in ATM kinase activity. Freshly isolated PBMCs were also shown to express low levels of p53 mRNA that is rapidly degraded (Voelkerding et al., 1995). Progressive stabilization of the p53 mRNA occurred during growth induction by incubation in the presence of phytohemagglutinin (PHA) and phorbol ester (TPA), whereby p53 mRNA steady state levels were increased 4.5 to 5 -fold. Accordingly, protein p53 was not detected in quiescent lymphocytes, but was detected in lymphocytes stimulated with PHA (Voelkerding et al., 1995).
It remains to be clarified whether $\gamma \mathrm{H} 2 \mathrm{~A} . \mathrm{X}$ is mainly involved in ATM mediated DNA DSB damage response (Fernandes-Capetillo et al., 2002) or whether it is also involved in recruitment of 53BP1 to sites of DNA DSB damage. Kang et al. (2005) studied interactions among H2A.X, Nbs1 and p53. They demonstrated that Nbs1, and not H2A.X is responsible for ATM-dependent suppression of interchromosomal rearrangement, which implies different roles of Nbs1 and H2A.X in DNA damage response. H2A. $X$ functions mainly as a downstream mediator of ATM kinase, in a pathway parallel to the p53 pathway. Nbs1 seems to have two major roles: ATM activator and an adapter to mediate ATM activity after DNA DSB damage.

The main aim of this study was to compare the reaction of quiescent and proliferating PHAstimulated PBMCs to $\gamma$-radiation and analyse changes of proteins related to repair of DNA damage and apoptosis, such as $\gamma$ H2A.X, p53 and phosphorylation of p53 at serine- 15 and -392 , and of p21. In this paper we demonstrate that even after irradiation the level of protein p53 (and its phosphorylation) are below detection limits of Western blot analysis in quiescent PBMCs, but p53 responds to $\gamma$-radiation in proliferating PHA-stimulated lymphocytes. PHAstimulation alone causes an increase in $\gamma$ H2A.X and p21. These proteins increase after IR in both quiescent and PHA-stimulated PBMCs, but with different dynamics. We also assess possible biodosimetric applications of these parameters.

\section{MATERIAL AND METHODS}

PBMCs and culture conditions. Peripheral blood mononuclear cells were isolated from volunteers' heparinized blood by centrifugation on the Histopaque-1077 (Sigma) cushion according to the manufacturer's instructions. After washing twice with cold PBS the cells were resuspended in Iscove's modified Dulbecco's medium (Sigma) supplemented with 20\% fetal bovine serum (PAA Laboratories $\mathrm{GmbH}$, Austria), $2 \mathrm{mmol} / \mathrm{l}$ glutamine (Sigma), 100 $\mathrm{UI} / \mathrm{ml}$ penicillin (Sigma) and $0.1 \mathrm{mg} / \mathrm{ml}$ streptomycin (Sigma) at the density of $5 \times 10^{5}$ cells $/ \mathrm{ml}$. The cell suspension was maintained in an incubator $\left(37^{\circ} \mathrm{C}\right.$, humidified atmosphere with $\left.5 \% \mathrm{CO}_{2}\right)$ till irradiation (2-3 h). For preparation of PHA-stimulated lymphoblasts, PHA (PHA-P, Sigma) was added at a concentration of $10 \mu \mathrm{g} / \mathrm{ml}$ and PBMCs were incubated $72 \mathrm{~h}$ in an incubator under the same conditions as unstimulated PBMCs.

In vitro irradiation. Cells in $10 \mathrm{ml}$ aliquots were transferred into $25 \mathrm{~cm}^{2}$ flasks (Nunc) and irradiated at room temp. using a ${ }^{60} \mathrm{Co}$ gamma $\mathrm{X}$-ray source. Doses below 10 Gy were delivered with a 
dose-rate of $0.4 \mathrm{~Gy} / \mathrm{min}$ at a distance of $1 \mathrm{~m}$ from the source, the dose of $10 \mathrm{~Gy}$ with $1.5 \mathrm{~Gy} / \mathrm{min}$ doserate and a distance of $0.5 \mathrm{~m}$ from the source. Immediately after irradiation the flasks were placed in a $37^{\circ} \mathrm{C}$ incubator with $5 \% \mathrm{CO}_{2}$ and aliquots of cells were collected at various time intervals after irradiation for analysis.

Cell cycle analysis. After different times of incubation, PBMCs were washed with cold PBS and fixed with $70 \%$ ethanol. For the detection of low molecular-weight fragments of DNA, the cells were incubated for $5 \mathrm{~min}$ at room temp. in buffer $\left(192 \mathrm{ml} 0.2 \mathrm{~mol} / 1 \mathrm{Na}_{2} \mathrm{HPO}_{4}+8 \mathrm{ml} 0.1 \mathrm{~mol} / 1\right.$ citric acid, $\mathrm{pH}$ 7.8) and then stained with propidium iodide (PI) in Vindelov's solution for $60 \mathrm{~min}$ at $37^{\circ} \mathrm{C}$. The DNA content was determined on flow cytometer Cytomics FC500 (Beckman Coulter, Hialeah, FL, USA) using a $15 \mathrm{~mW}$ argon-ion laser for $488 \mathrm{~nm}$ excitation; the total emission above 560 $\mathrm{nm}$ was recorded. List mode data were analyzed using Multicycle AV software (Phoenix Flow Systems, Inc., San Diego, CA, USA). A minimum of three independent measurements were performed.

CD25 expression. Expression of CD25 was determined by anti-CD25-PE (clone 33B3.1, Beckman Coulter). Flow cytometric analysis was performed on a Coulter Epics XL flow cytometer equipped with a $15 \mathrm{~mW}$ argon-ion laser for 488 $\mathrm{nm}$ excitation (Coulter Electronic, Hialeah, FL, USA). A minimum of 10000 cells were collected for each 2-colour sample in a list mode file format. List mode data was analyzed using Epics XL System II software (Coulter Electronic, Hialeah, FL, USA).

Three-color flow cytometry. PBMCs were washed in ice-cold washing and staining buffer (WSB, PBS containing $0.2 \%$ gelatin and $0.1 \% \mathrm{NaN}_{3}$ ) and kept in the cold during subsequent processing to prevent further apoptosis development. For visualization of the $\mathrm{T}$ lymphocyte subset surface immunostaining using the mouse anti-human CD3/ PB (clone UCHT1, DakoCytomation) was chosen. After 15 min incubation and a single wash cycle (2 ml WSB, centrifugation, vortexing) the cells were treated with fluorescein isothiocyanate-conjugated Annexin V (A-FITC) and propidium iodide (PI) from the Apoptest kit (DakoCytomation) according to the manufacturer's instructions. Flow cytometry (FCM) was performed on a nine-color CyAn (DakoCytomation) flow cytometer. A minimum of 50000 events were analyzed in each sample and the results were evaluated using the Summit v.4.3 software. Too small objects including cell debris and the majority of non-adherent monocytes were excluded from analysis by a standard approach using the "lymphogate" region in the forward and side (right angle) scatter characteristics (FSC and
SSC, respectively). Lymphogate was carefully set up to include smaller cells in the later stages of apoptosis into the analyzed population.

Western blotting. PBMCs were washed with a PBS at various times after irradiation. The lysates containing an equal amount of protein $(30 \mu \mathrm{g})$ were loaded onto different lanes of a polyacrylamide gel. After electrophoresis, the separated proteins were transferred to a PVDF membrane. The membranes were blocked in Tris-buffered saline containing $0.05 \%$ Tween 20 and 5\% non-fat dry milk and then incubated with a primary antibody (p53 and phosphorylated p53 (serine-392) from Exbio, p21 and $\gamma \mathrm{H} 2 \mathrm{AX}$ from Cell Signaling) at $4^{\circ} \mathrm{C}$ overnight. After washing, the blots were incubated with a secondary antibody (DakoCytomation) and the signal was developed with a chemiluminiscence detection kit (Boehringer).

ELISA. For quantitative assay of p53 and phosphorylated p53 (serine-15) PathScan Sandwich ELISA kits by Cell Signaling Technology were used. The optical density (OD) measured at $450 \mathrm{~nm}$ was plotted against dose D (in Gy) and the resulting curve turned out to be of sigmoidal shape compatible with Michaelis-Menten kinetics

$\mathrm{OD}=\mathrm{a}+\mathrm{b} \times \mathrm{D} /(\mathrm{c}+\mathrm{D})$

This was checked with the help of a Lineweaver-Burk plot, showing direct proportionality between 1/D and 1/OD (Lineweaver \& Burk, 1934).

Immunocytochemistry. The cells were fixed with $4 \%$ freshly prepared paraformaldehyde for $10 \mathrm{~min}$ at room temp., rinsed quickly in PBS, then washed $3 \times 5$ min in PBS, permeabilized in $0.2 \%$ Triton $\mathrm{X}-100 / \mathrm{PBS}$ for $15 \mathrm{~min}$ at room temp., rinsed in PBS and washed $2 \times 5 \mathrm{~min}$. Before incubation with primary antibodies (overnight at $4^{\circ} \mathrm{C}$ ), the cells were blocked with $7 \%$ inactivated FCS $+2 \%$ bovine serum albumin in PBS for $30 \mathrm{~min}$ at room temp. For detection of $\gamma$ H2A.X mouse monoclonal anti-phospho-Histone H2A.X (Upstate) was used. Secondary antibody: Affinity pure donkey anti-mouse-FITCconjugated and affinity pure donkey anti-rabbit-Cy3conjugated were purchased from Jackson Laboratory (Bar Harbor, ME, USA). Antibodies were applied to each slide (after their pre-incubation with 5.5\% donkey serum in PBS for $30 \mathrm{~min}$ at room temp.) and incubation for $1 \mathrm{~h}$ in the dark followed by washing $(3 \times 5 \mathrm{~min})$ in PBS. Counterstaining was performed by TOPRO-3 (Molecular Probes, Eugene, OR, USA) in saline sodium citrate prepared fresh from the stock solution.

Images were obtained on a high-resolution confocal cytometer based on a completely automated Leica DM RXA fluorescence microscope equipped with CSU-10a confocal unit (Yokogawa, Japan) and 
a CoolSnap HQ charged-coupled device camera (Photometrix, Melbourne, Australia). Forty optical sections of $0.3 \mu \mathrm{m}$ were acquired for each nucleus and stored in the computer memory. The exposition time and dynamic range of camera in the red, green and blue channels were adjusted to the same values for all slides to obtain quantitatively comparable images. Integral optical density (IOD) was measured using image analysis software ImagePro 4.11 (MediaCybernetics, USA).

\section{RESULTS}

\section{Stimulation by PHA}

The reaction of PBMCs to ionizing radiation was evaluated using non-stimulated and PHA-stimulated cells. PBMCs circulating in peripheral blood are predominantly present in $\mathrm{G}_{0}$ phase of cell cycle, in our case only $0.7 \%$ of the cells were in $S$ phase (Fig. 1A, B). The cells did not express CD25 antigen, i.e. the alpha chain of the receptor for interleukin-2 (Fig. 1C). Long stimulation (72 h) by $10 \mu \mathrm{g} / \mathrm{ml}$ PHA caused activation of T-lymphocytes and induced CD25 on almost all cells (Fig. 1C). DNA content analysis revealed an increase in the percentage of cells in S phase, with a maximum $48 \mathrm{~h}$ after the beginning of stimulation, when $12.2 \%$ of the cells were in $S$ phase (Fig. 1C).

\section{Apoptosis induction}

Apoptosis induction in T-lymphocytes (CD3+) was analysed by FCM 24 and $72 \mathrm{~h}$ after the irradiation by the dose of $4 \mathrm{~Gy}$. The effect of irradiation on non-stimulated and PHA-stimulated PBMC was compared. Separated PBMC were cultivated for 24 $\mathrm{h}$ and subsequently irradiated by the dose of $4 \mathrm{~Gy}$. PHA-stimulated lymphocytes were incubated with PHA for $72 \mathrm{~h}$ and subsequently irradiated by the dose of 4 Gy. In both groups apoptosis induction was evaluated 24 and $72 \mathrm{~h}$ after irradiation. Figure 2 shows representative results of FCM analysis of radiation-induced apoptosis in $\mathrm{CD}^{+}$lymphocytes using dual staining by Annexin V (A) and propidium iodide (PI). This method allows detection of live cells $\left(\mathrm{A}^{-} \mathrm{PI}^{-}\right)$, early apoptotic cells $\left(\mathrm{A}^{+} \mathrm{PI}^{-}\right)$, and late apoptotic cells $\left(\mathrm{A}^{+} \mathrm{PI}^{+}\right)$.

Table 1 summarizes mean values of radiation-induced apoptosis in PBMC samples obtained from three different blood donors. It is apparent that 72 h-long stimulation causes increase in early apoptotic cells (37.94\% $\mathrm{A}^{+} \mathrm{PI}^{-}$versus $16.71 \%$ in control). Irradiation by the dose of $4 \mathrm{~Gy}$ increases $\mathrm{A}^{+}$cells

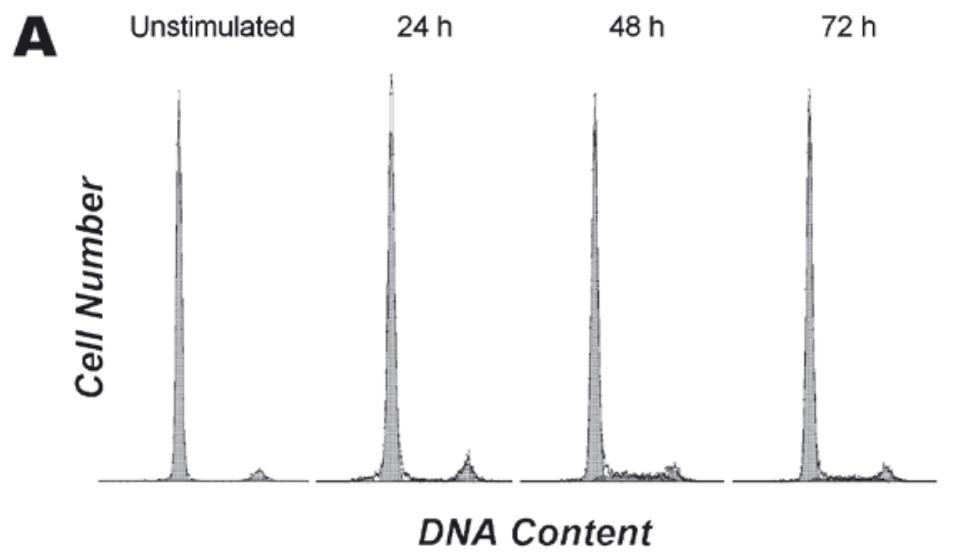

B

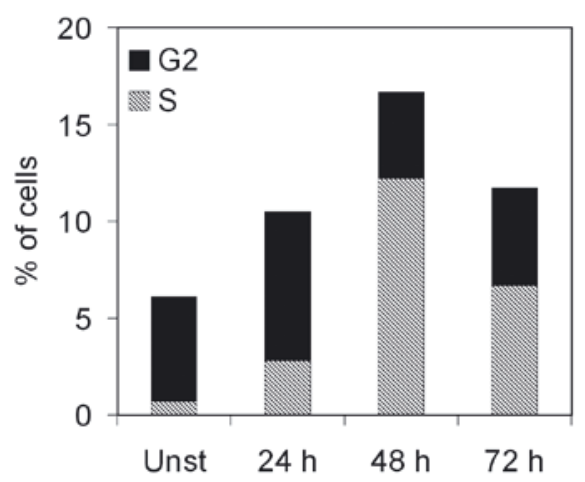

Figure 1. Stimulation of lymphocytes by PHA.

A, B. Dynamics of cell cycle changes induced in PBMCs by in vitro stimulation by $10 \mu \mathrm{g} / \mathrm{ml}$ PHA. The amount of DNA in each cell was determined after PI staining by flow-cytometric analysis. The PBMCs entered the cell cycle and the number of cells in the $S$ and $G_{2}$ phases increased after PHA-stimulation. C. Expression of CD25 antigen and forward scatter (corresponding to cell size) analysis of T-lymphocytes $\left(\mathrm{CD}^{+}\right)$after $72 \mathrm{~h}$ of stimulation by PHA. While only 3.5\% of control T-lymphocytes are CD25+, this fraction increased to $95.6 \%$ after the stimulation by PHA. 


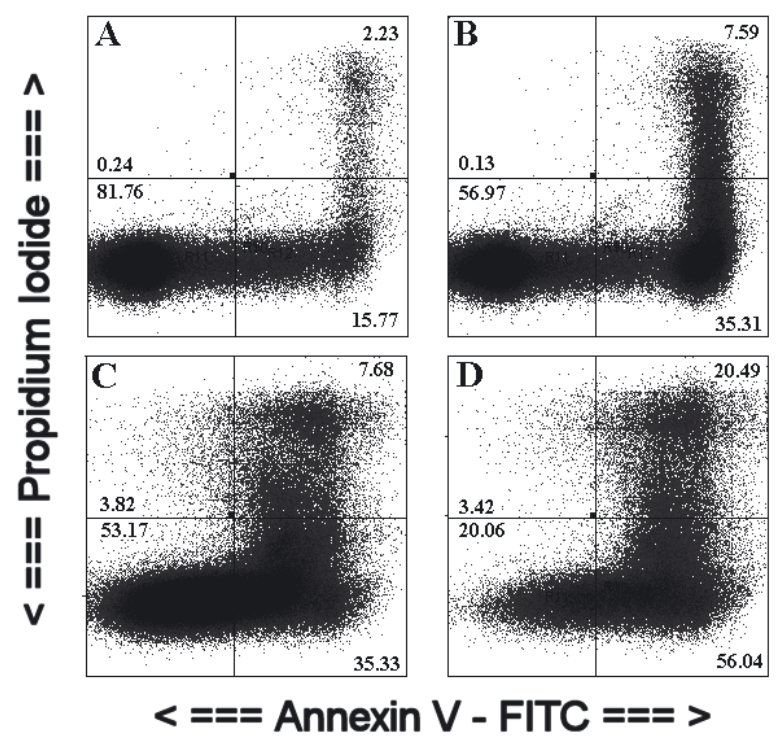

Figure 2. Apoptosis induction $24 \mathrm{~h}$ after irradiation by a dose of $4 \mathrm{~Gy}$ in quiescent and PHA-stimulated PBMCs. Representative results of multiparameter flow cytometric analysis of in vitro irradiated (4 Gy) and subsequently cultivated (24 h) human PBMC stained with anti-CD3/PB monoclonal antibody and counterstained with Apoptest ${ }^{\mathrm{TM}}$. A. control $\mathrm{CD}^{+}$lymphocytes; B. irradiated $\mathrm{CD}^{+}$lymphocytes; C. $\mathrm{CD}^{+}$lymphocytes after $96 \mathrm{~h}$ stimulation with PHA; D. $\mathrm{CD}^{+}$lymphocytes after $96 \mathrm{~h}$ stimulation with PHA and $24 \mathrm{~h}$ after irradiation.

to $37.51 \% 24 \mathrm{~h}$ after the irradiation and further to $69.68 \% 72 \mathrm{~h}$ after the irradiation. The majority of the apoptotic cells were $\mathrm{A}^{+} \mathrm{PI}^{-}$cells, i.e. early apoptotic. Also in the PHA-stimulated group irradiation by the dose of 4 Gy caused an increase in apoptotic cells to $70.64 \%$ (24 h after irradiation) and 65.22\% (72 h after irradiation)

\section{Detection of ionizing radiation induced foci}

At the site of DSB in the DNA, protein complexes are assembled, which form optically discernible foci - IRIF. These sites can be identified by detection of the phosphorylated form of histone H2A.X by an immunocytochemical method on confocal microscope. We identified $\gamma$ H2A.X foci in quiescent PBMCs $1 \mathrm{~h}$ after irradiation by the doses

Table 1. Apoptosis induction $24 \mathrm{~h}$ after irradiation by the dose of $4 \mathrm{~Gy}$ in quiescent and PHA-stimulated PBMCs

\begin{tabular}{llllll}
\hline & & \multicolumn{2}{l}{ Nonstimulated ly } & \multicolumn{2}{l}{ PHA stimulated ly } \\
\cline { 3 - 6 } & & $\mathrm{A}^{+}$ & $\mathrm{A}^{+} \mathrm{PI}^{-}$ & $\mathrm{A}^{+}$ & $\mathrm{A}^{+} \mathrm{PI}^{-}$ \\
\hline $24 \mathrm{~h}$ & $\mathrm{C}$ & $16.71 \pm 4.53$ & $13.44 \pm 4.55$ & $42.99 \pm 4.97$ & $37.94 \pm 6.57$ \\
& $4 \mathrm{~Gy}$ & $37.51 \pm 3.20$ & $27.24 \pm 2.32$ & $70.64 \pm 11.57$ & $54.24 \pm 4.42$ \\
$72 \mathrm{~h}$ & $\mathrm{C}$ & $22.97 \pm 7.76$ & $15.25 \pm 5.72$ & $51.46 \pm 5.61$ & $41.34 \pm 0.95$ \\
& $4 \mathrm{~Gy}$ & $69.68 \pm 7.95$ & $40.28 \pm 2.39$ & $65.22 \pm 12.66$ & $49.13 \pm 10.41$ \\
\hline
\end{tabular}

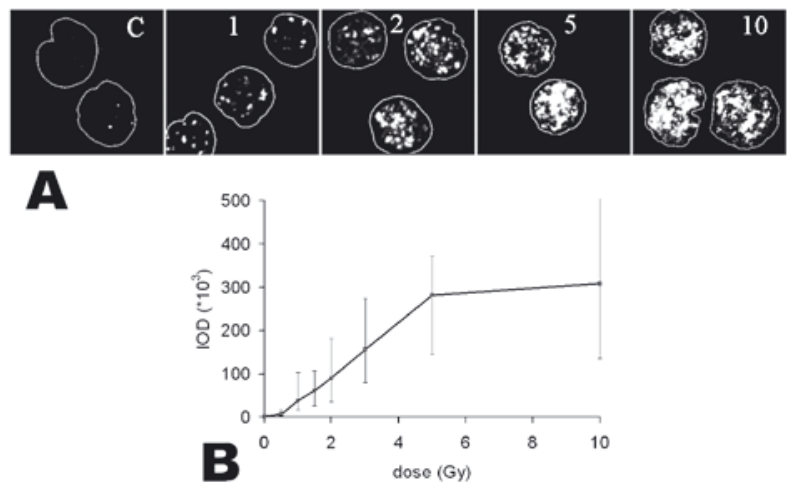

Figure 3. Phosphorylation of histone H2A.X on serine139 in quiescent PBMCs $1 \mathrm{~h}$ after irradiation.

A. Examples of nuclei of control (C) and irradiated PBMCs (dose 1, 2, 5 and $10 \mathrm{~Gy}$ ). One hour after irradiation the cells were fixed and immunostained with antibody against $\gamma$ H2A.X. Cell nuclei were counterstained by TOPRO3, and are marked by solid line. B. This graph summarizes quantification of the intensity of green $(\gamma \mathrm{H} 2 \mathrm{~A} . \mathrm{X}-$ FITC) fluorescence measured as integral optical density of each cell. At least 50 cells were analyzed in each sample. Median values and 1st and 3rd quartile are indicated.

0.5-10 Gy (Fig. 3A). The intensity of the phosphorylation in irradiated PMBCs is such that it seems to have a potential as a biodosimetric marker: the integral optical density was measured using image analysis (Fig. 3B). In the dose range $0.5-5$ Gy a linear dose-dependence was observed.

Protein changes induced by radiation are different in quiescent and stimulated PBMCs

We analyzed changes in proteins related to DNA damage repair and apoptosis using the Western blot method in quiescent and stimulated PBMCs. The cells were irradiated by a dose of $4 \mathrm{~Gy}$ and the dynamics of the process were studied.

In quiescent lymphocytes, $\gamma \mathrm{H} 2 \mathrm{~A} . \mathrm{X}$ was not detected early after irradiation ( 1 and $4 \mathrm{~h}$ ), but increased at $24-72 \mathrm{~h}$. This increase in $\gamma \mathrm{H} 2 \mathrm{~A}$.X detectable by Western blot occurred during apoptosis, which was confirmed by caspase cleavage of lamin $\mathrm{B}$. We also detected an increase in cell cycle regulator p21 24-72 h after irradiation. This increase was not accompanied by a detectable increase in p53 or by p53 phosphorylation (Fig. 4A).

In PHA stimulated cells slight phosphorylation of H2A.X was detected even without irradiation. The phosphorylation increased from $1 \mathrm{~h}$ after the irradiation onwards, with a maximum at $24 \mathrm{~h}$. PHA stimulation caused a significant increase in the p53 amount in comparison with quiescent PBMCs, 
A Quiescent PBMCs

B PHA-stimulated PBMCs

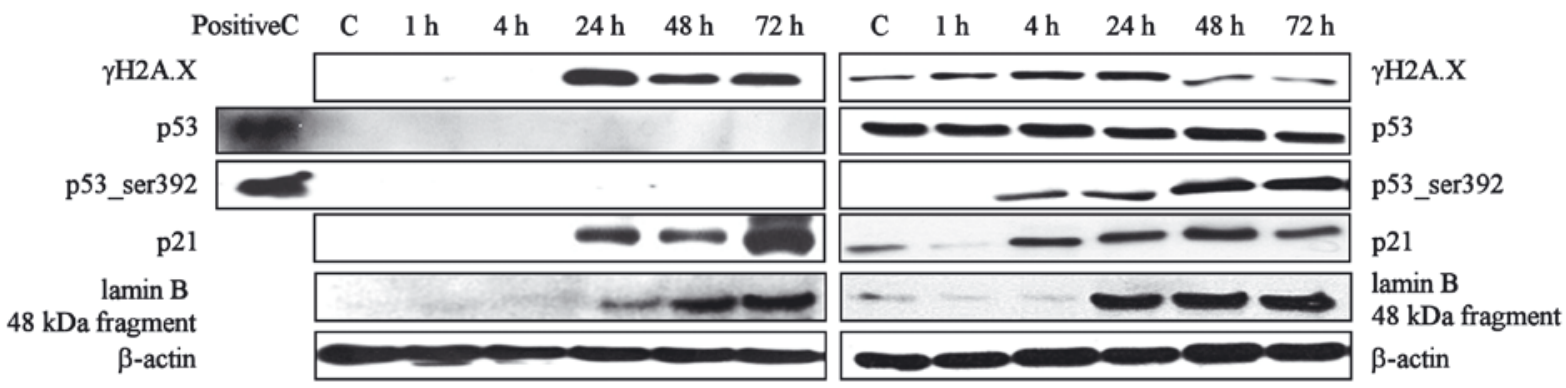

Figure 4. Comparison of changes in $\gamma \mathrm{H} 2 \mathrm{~A} . \mathrm{X}, \mathrm{p} 53$, p53 phosphorylated at serine-392, p21 levels and apoptosis during $72 \mathrm{~h}$ after irradiation by a dose of $4 \mathrm{~Gy}$ in quiescent and PHA-stimulated PBMCs.

A. Freshly isolated quiescent PBMCs. The cells were isolated from peripheral blood, irradiated by the dose of 4 Gy and then incubated for 1-72 h. MOLT-4 cells ( $4 \mathrm{~h}$ after the irradiation by the dose of 4 Gy) were used as positive control for p53 detection. B. PHA-stimulated proliferating PBMCs. Isolated PBMCs were stimulated with PHA $(72 \mathrm{~h}, 10 \mu \mathrm{g} / \mathrm{ml})$, irradiated by the dose of $4 \mathrm{~Gy}$ and then incubated for 1-72 h. Representative Western blots are shown. The cells were lysed and analysed at the time intervals indicated. After irradiation, the level of protein p53 (and its phosphorylation) was below detection limits of Western blot analysis at quiescent PBMCs, but p53 responded to $\gamma$-radiation in proliferating PHA-stimulated PBMCs. PHA-stimulation also caused an increase in $\gamma \mathrm{H} 2 \mathrm{~A} . \mathrm{X}$ and p21. These proteins increase after IR in both quiescent and PHA-stimulated PBMCs, but with different dynamic. Apoptosis was detected by analysis of lamin B cleavage - a $68-\mathrm{kDa}$ nuclear protein is cleaved into a $48-\mathrm{kDa}$ fragment by active caspases when apoptosis is induced. $\beta$-Actin was used as a loading control.

but this p53 was not phosphorylated. Further upregulation of p53 was detected 1-72 $\mathrm{h}$ after irradiation. From $4 \mathrm{~h}$ after irradiation onwards, phosphorylation of p53 at serine-392 was detected. Furthermore, protein p21 was induced in non-irradiated PHA stimulated cells and its amount increased after irradiation, with a maximum increase at $48 \mathrm{~h}$ (Fig. 4B).

Dose-dependence of radiation-induced changes in PHA-stimulated cells

Dose-dependence of changes in $\gamma \mathrm{H} 2 \mathrm{~A} . \mathrm{X}$, p53, p53 phosphorylated at serine-392, and p21 in PHA-

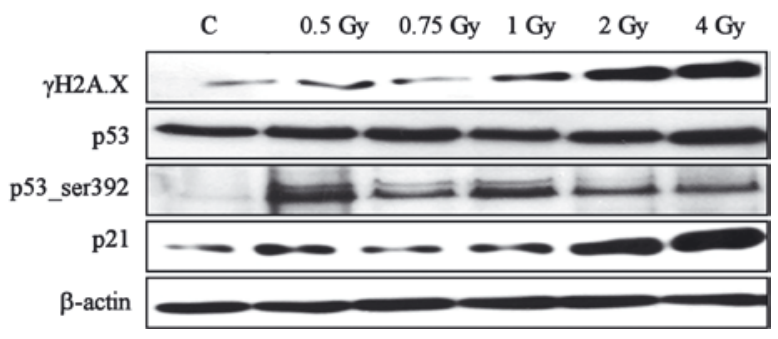

Figure 5. Dose dependence of changes in $\gamma \mathrm{H} 2 \mathrm{~A} . \mathrm{X}$, p53, p53 phosphorylated at serine-392, and p21 $4 \mathrm{~h}$ after irradiation of PHA-stimulated PBMCs.

Isolated PBMCs were stimulated with PHA (72 h, $10 \mu \mathrm{g} /$ $\mathrm{ml})$, irradiated with the indicated dose, incubated for $4 \mathrm{~h}$, lysed and analyzed by Western blot. Representative Western blots are shown. A dose-dependent response was observed in the dose range 0.5-4 Gy for the phosphorylation of H2A.X at serine-139 and for the increase in p21. Neither p53 nor p53 phosphorylated at serine-392 exhibited a dose-dependent response. $\beta$-Actin was used as a loading control. stimulated lymphocytes were evaluated $4 \mathrm{~h}$ after irradiation by Western blot analysis. Both $\gamma \mathrm{H} 2 \mathrm{~A}$. $X$ and p21, but not p53 and p53 phosphorylation at serine-392 showed a dose-dependent increase over the dose range studied (0.5-4 Gy) (Fig. 5).

A very sensitive method for quantitative measurements of p53 and p53 phosphorylated at serine-15 is the so-called sandwich ELISA. Figure 5 shows a dose-dependent increase of p53 phosphorylation at serine-15 $4 \mathrm{~h}$ after irradiation over the dose range 0.5-7.5 Gy by using Western blot and ELISA methods. We also measured the amount of total p53, but similar to our findings with the Western blot analysis, no dose-dependence was observed (Fig. 6).

\section{DISCUSSION}

Many studies (Schultz et al., 2000; Stiff et al., 2004; Bekker-Jensen et al., 2006) have shown that one of the earliest responses of eukaryotic cells to DSB in the DNA caused by IR is the phosphorylation of histone H2A.X at serine-139. This modification occurs in DSB flanking chromatin within minutes after irradiation. At the same time various other proteins are recruited to these sites, forming intranuclear "ionizing radiation induced foci" (IRIF). The most important function of IRIF is repair of radiation-induced DNA damage. A significant decrease in the number of initially formed IRIF detected by immunocytochemical evaluation of live cells is apparent during 24 hafter irradiation. The initial 


\section{Phosphorylation of p53 (Ser 15)}
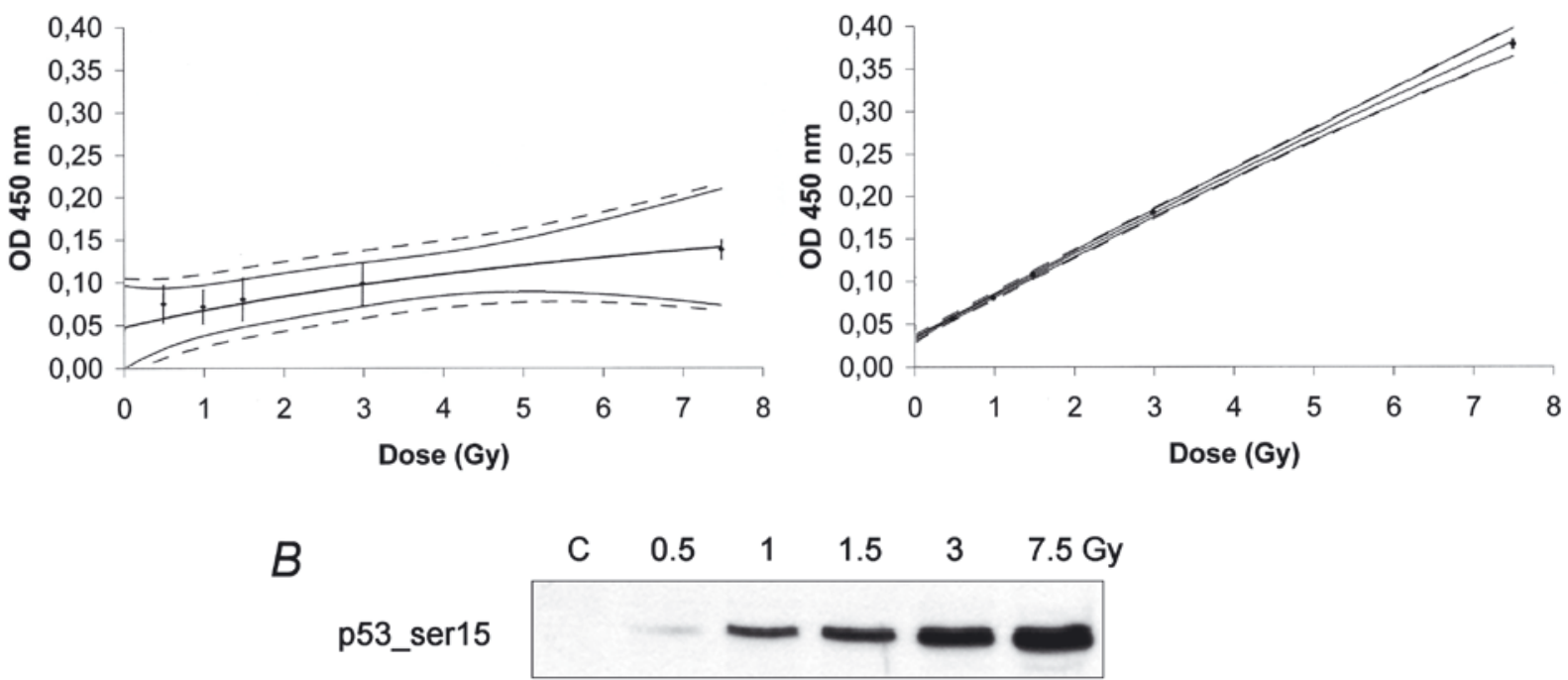

Figure 6. Dose dependence of changes in p53 and p53 phosphorylated at serine-15 over the dose range $0.5-7.5 \mathrm{~Gy}, 4 \mathrm{~h}$ after irradiation of PHA-stimulated PBMCs.

$A$. Isolated PBMCs were irradiated with the indicated dose, incubated for $4 \mathrm{~h}$, and analysed by ELISA. The optical density OD at $450 \mathrm{~nm}$ was plotted against dose D (in Gy) and the resulting curve turned out to be compatible with Michaelis-Menten kinetics. The equation of the fitted curve was $\mathrm{OD}=\mathrm{a}+\mathrm{b} \times \mathrm{D} /(\mathrm{c}+\mathrm{D})$ ). The calculated parameters ( \pm standard deviation from 6 experiments) were as follows:

\begin{tabular}{llll}
\hline & a & $b$ & $c$ \\
& (OD at 0 Gy) & (maximum OD) & (D for half-maximum OD) \\
\hline p53 & $0.050 \pm 0.007$ & $0.164 \pm 0.057$ & $6.4 \pm 4.6$ Gy \\
p53_ser 15 & $0.034 \pm 0.006$ & $4.0 \pm 1.2$ & $75 \pm 23$ Gy \\
\hline
\end{tabular}

While p53 did not exhibit a dose-dependent increase (as also demonstrated in Fig. 4), the phosphorylation of p53 at serine-15 exhibited a dose-dependence over the whole dose range studied (0.5-7.5 Gy).

$B$. Isolated PBMCs were irradiated with the indicated dose, incubated for $4 \mathrm{~h}$, lysed and analyzed by Western blot. Representative Western blots are shown. A dose-dependent response was observed in the dose range 0.5-7.5 Gy for the phosphorylation of p53 at serine-15.

increase in $\gamma \mathrm{H} 2 \mathrm{~A} . \mathrm{X}$ phosphorylation is dependent upon ATM kinase activation (Banáth et al., 2004). ATM kinase is activated quickly after DNA damage and triggers down-stream pathways of DNA repair and/or cell death. Among the proteins detected in IRIF are 53BP1, Nbs1, Mre11, Rad50, BRCA1, Mdc1 and ATM (Bekker-Jensen et al., 2006). In this paper we have shown that the increase in $\gamma \mathrm{H} 2 \mathrm{~A} . \mathrm{X}$ foci detected by confocal microscopy and quantified by image analysis $1 \mathrm{~h}$ after in vitro irradiation of quiescent lymphocytes is dose-dependent in the dose range 0.5-5 Gy. However, using Western blot analysis this early increase in $\gamma \mathrm{H} 2 \mathrm{~A} . \mathrm{X}$ is not detectable in quiescent lymphocytes. Western blot technique can detect $\gamma$ H2A.X increase only at later times, when the phosphorylation of H2A.X is related to the onset of apoptosis (24-72 h after irradiation by the dose of $4 \mathrm{~Gy}$ ). These data are in good agreement with the recent suggestions by Mukherjee et al. (2006) that H2A.X is phosphorylated also during
DNA fragmentation occurring in the course of apoptosis. Mukherjee et al. (2006) found that during apoptosis, H2A.X phosphorylation is catalyzed by DNA-PKcs, while ATM is dispensable for the process. In our experiments immunocytochemical detection of $\gamma \mathrm{H} 2 \mathrm{~A} . \mathrm{X}$ by confocal microscopy is more sensitive than Western blot analysis, reveals initial $\gamma \mathrm{H} 2 \mathrm{~A} . \mathrm{X}$ related to IRIF formation and is more suitable for quantification by image analysis.

The level of H2A.X phosphorylation increased after stimulation of PBMC by PHA (72 h, $10 \mu \mathrm{g} / \mathrm{ml})$ and as shown here it was detectable by Western blot analysis. The increase in $\gamma \mathrm{H} 2 \mathrm{~A} . \mathrm{X}$ that we detected by Western blot $4 \mathrm{~h}$ after irradiation of stimulated lymphocytes was dose dependent. These data are in good agreement with those of Hamasaki et al. (2007), who used a flow cytometry system for measurement of IR-induced $\gamma \mathrm{H} 2 \mathrm{~A} . \mathrm{X}$ in quiescent and PHA stimulated lymphocytes $4 \mathrm{~h}$ after the irradiation. It can be concluded that measurement of $\gamma \mathrm{H} 2 \mathrm{~A} . \mathrm{X}$ during the 
first hours after the irradiation is a good marker of the received dose of radiation.

The effect of two different genotoxic stressors - actinomycin (DNA-intercalating agent) and irradiation - on T cells in the G0/G1 phase was compared by Porcedda et al. (2006). They showed that while actinomycin induces DSB in normal quiescent $\mathrm{T}$ lymphocytes and targets them to apoptosis, T cells from AT and NBS patients resist actinomycin-induced apoptosis and survive. Following irradiation by the dose of 2 Gy quiescent $\mathrm{T}$ cells from normal donors form 30 IRIF per cell on the average, but normal $\mathrm{T}$ cells resolve virtually all damage within $72 \mathrm{~h}$ (average number of IRIF decreases to 0.5 per cell) and survive. T cells from AT and NBS patients also survive, despite the maintenance of $4 \gamma \mathrm{H} 2 \mathrm{~A}$.X foci per cell after $72 \mathrm{~h}$. They also compared irradiation dose 0.5 Gy and actinomycin in concentration $0.05 \mu \mathrm{g} / \mathrm{ml}$, both of which induce 8 foci per cell after $1 \mathrm{~h}$. Twenty four hours after exposure to actinomycin the residual damage was $72-100 \%$, while after irradiation it was lower, 9-20\%. Although both agents induce the same number of foci in the cells, it is questionable whether the same molecular pathway is triggered by actinomycin and irradiation. Phosphorylation of kinase ATM was significantly higher after irradiation than after exposure to actinomycin. On the other hand, actinomycin caused a more intensive and longer increase in p53 and its phosphorylation on serine- 15 .

When p53 receives information about DNA damage within the cell, it may arrest the cell's advance through its growth- and division-cycle and, at the same time, orchestrate localized responses to facilitate the repair of damage. However, under certain conditions, p53 can also emit signals that awaken the normally latent suicide program - apoptosis (Weinberg, 2007). Increase in p53 was detected in many cell types after exposure to IR, UV radiation, and chemotherapeuticals which damage DNA. Measurement of p53 protein levels indicated that they could vary drastically from one cell type to another (Weinberg, 2007). Generally, increase in p53 is predominantly regulated by blocking its degradation in proteasomes (Weinberg, 2007). Irradiation of leukemic MOLT-4 cells by IR induces phosphorylation of ATM, which in turn phosphorylates p53 (which prevents its degradation) and its negative regulator $\mathrm{Mdm} 2$ (a ubiquitin ligase) (Tichý et al., 2007). While MOLT-4 cells derived from T-lymphocytic leukemia have high levels of p53 (Szkanderová et al., 2003), we did not detect p53 nor its phosphorylation on serine-392 in quiescent lymphocytes, not even after $\gamma$ irradiation. This does correspond with findings of Jones et al. (2004), who did not detect significant levels of p53 protein nor its phosphorylation in PBMCs irradiated by UVC and concluded that UVC-induced ATR-p53 pathway is downregulated in non-cycling lymphocytes. Voelkerding et al. (1995) observed very low expression of p53 mRNA in $G_{0}$ quiescent lymphocytes, and its rapid degradation with a half life of $1 \mathrm{~h}$. They also demonstrated that PHA and TPA stimulation leads to stabilization of p53 mRNA in the nucleus, half-life increased to 6 h. Fukao et al. (1999) showed that in PBMCs in a state of quiescence ATM kinase is present at low levels and increases approx. 6-10-fold in response to mitogenic stimuli (PHA $10 \mu \mathrm{g} / \mathrm{ml}$ ) reaching a maximum after 3-4 days. Two hours after irradiation by the dose of 6 Gy of stimulated PBMCs they detect p53 and p21 by Western blot analysis. Our findings correspond with their data. We compared the dynamics of p53 induction after irradiation by IR in both quiescent and stimulated lymphocytes. p53 increase was observed only in stimulated lymphocytes, as was p53 phosphorylation at serines-392 and -15. The increase in the amount of p53 was not dose-dependent $4 \mathrm{~h}$ after the irradiation. On the other hand, phosphorylation of p53 at serine- 15 analyzed $4 \mathrm{~h}$ after the irradiation is dose-dependent over the studied doserange (0.5-7.5 Gy).

Despite the fact that p53 was not detected in quiescent lymphocytes and a reaction to irradiation was not observed either, p21 levels increased after irradiation in both quiescent and stimulated lymphocytes in a dose-dependent manner. p21 (also known as cyclin-dependent kinase inhibitor 1A - CDKN1A) inhibits activity of cyclin-CDK2 and cyclin-CDK4 complexes, which causes cell cycle arrest in G1/S phase and allows DNA-damage repair. It was shown that histone deacetylase inhibitors induce increased expression of p21 by both p53-dependent and p53 independent mechanisms (Ocker \& Schineider-Stock, 2007) and that this activation includes many other factors such as ATM (Ju \& Muller, 2003) or c-myc (Zhao et al., 2006). It seems that the main pathway involved in p21 induction by histone deacetylase inhibitors is triggered through Sp1/Sp3 pathway activation. On the other hand, Pettitt et al. (2001) studied radiosensitivity of B-cell chronic lymphocytic leukemia. They detected increase in p53 and p21 and high sensitivity to radiation-induced apoptosis only in p53 wild type leukemias. When p53 was absent, no expression of p21 was found after irradiation and the cells were more radioresistant. In cells of human leukemia HL-60 and U937 exit from cell cycle is a prerequisite for terminal differentiation and p21 is induced during terminal differentiation of cells (Gartel \& Tyner, 1999). In some cell types p21 expression protects the cells from p53-depend- 
ent apoptosis induction (Gorospe et al., 1997). Low expression of p53 in $\mathrm{T}$ lymphocytes irradiated by the dose of 2 Gy in contrast to high expression after actinomycin treatment (Porcedda et al., 2006), and low p53 and high expression of p21 in quiescent lymphocytes after irradiation by the dose of 4 Gy detected in our study indicate that increased p21 in lymphocytes enhances repair of radiationinduced damage and prevents apoptosis.

Apoptosis induction in quiescent lymphocytes was described in the study of Vokurková et al. (2006). It proves that even after exposure to a high lethal dose of 7 Gy apoptosis is not induced within $6 \mathrm{~h}$ after irradiation. Apoptotic cells detected by Annexin $\mathrm{V}$ binding were found only $16 \mathrm{~h}$ after the irradiation and $48 \mathrm{~h}$ after the irradiation $80 \%$ of lymphocytes were $\mathrm{A}^{+}$. When sensitivity of different $\mathrm{T}$ lymphocyte subpopulations $\left(\mathrm{CD}^{+} \mathrm{CD}^{+}\right.$, $\mathrm{CD}^{+} \mathrm{CD}^{+}$and $\mathrm{CD}^{-} \mathrm{CD}^{+}$) was studied, the most radiosensitive cells were natural killer cells $\mathrm{CD}^{-}$ $\mathrm{CD}^{+}$.

In present study we compare apoptosis induction in quiescent $\mathrm{CD}^{+}$and PHA-stimulated T lymphocytes. We prove that $72 \mathrm{~h}$-long stimulation of T lymphocytes by PHA induces apoptosis (detected by Annexin $\mathrm{V}$ binding and lamin $\mathrm{B}$ cleavage). Apoptotic cells were mostly $\mathrm{A}^{+} / \mathrm{PI}^{-}$, which indicates an early stage of apoptosis. Also apoptosis was detected in unstimulated and PHA-stimulated cells from $24 \mathrm{~h}$ after the irradiation by the dose of 4 Gy onwards. In both, unstimulated and PHAstimulated cells $65-70 \%$ of cells were apoptotic 72 $\mathrm{h}$ after the irradiation.

Phosphorylation of p53 in response to DNA damage is one mechanism by which its activity can be modulated. Serine-15 was identified as a site on p53 phosphorylated in response to DNA damage induced by UV or IR (Siliciano et al., 1997; Shieh et al., 1997) UV and IR action is different with respect to phosphorylation of p53 at serine-392 in colon cancer cells RKO (Kapoor \& Lozano, 1998). However, using T-cell leukemic cells MOLT-4 phosphorylation of p53 at serine-392 was shown after IR as well (Szkanderová et al., 2003). As we demonstrate in this paper, IR induces phosphorylation of p53 at both serines-15 and -392 in PHA stimulated human lymphocytes. However, phosphorylation at serine- 15 was dose-dependent, while phosphorylation at serine-392 was not.

In this paper we have shown that irradiation of stimulated lymphocytes causes an increase in phosphorylation of histone H2A.X, an increase in p53 and its phosphorylation, and an increase in p21. Immunocytochemical detection of $\gamma \mathrm{H} 2 \mathrm{~A}$. $X$ and ELISA measurement of p53 phosphorylated on serine-15 can be used as indicator of received dose of IR.

\section{Acknowledgements}

The authors would like to thank the Ministry of Defence of the Czech Republic for financial support. (projects MO0FVZ0000501 and OBUKHK205001).

\section{REFERENCES}

Bakkenist CJ, Kastan MB (2003) DNA damage activates ATM through intermolecular autophosphorylation and dimer dissociation. Nature 421: 486-488.

Banáth JP, MacPhail SH, Olive PL (2004) Radiation sensitivity, H2A.X phosphorylation, and kinetics of repair of DNA strand breaks in irradiated cervical cancer cell lineas. Cancer Res 64: 7144-7149.

Bekker-Jensen S, Lukas C, Kitagawa R, Melander F, Kastan MB, Bartek J, Lukas J (2006) Spatial organization of the mammalian genome surveillance machinery in response to DNA strand breaks. Cell Biol 173: 195-206.

Cornelissen M, Philippé J, De Sitter S, De Ridder L (2002) Annexin $\mathrm{V}$ expression in apoptotic peripheral blood lymphocytes. An electron microscopic evaluation. Apoptosis 7: 41-47.

Fernandez-Capetillo O, Chen HT, Celeste A, Ward I, Romanienko PJ, Morales JC, Naka K, Xia Z, CameriniOtero RD, Motoyama N, Carpenter PB, Bonner WM, Chen J, Nussenzweig A (2002) DNA damage-induced G2-M checkpoint activation by histone H2AX and 53BP1. Nat Cell Biol 4: 993-997.

Fukao T, Kaneko H, Birrell G, Gatei M, Tashita H, Yoshida T, Cross S, Kedar P, Watters D, Khana KK, Misko I, Kondo N, Lavin MF (1999) ATM is upregulated during the mitogenic response in peripheral blood mononuclear cells. Blood 94: 1998-2006.

Gartel AL, Tyner AL (1999) Transcriptional regulation of the p21 (WAF1/CIP1) gene. Exp Cell Res 246: 280-289.

Gorospe M, Cirielli C, Wang X, Seth P, Capogrossi M, Holbrook N (1997) p21 (WAF1/CIP1) protects against p53-mediated apoptosis of human melanoma cells. Oncogene 14: 929-935.

Hamasaki K, Imai K, Nakachi K, Takahashi N, Kodama Y, Kusunoki Y( 2007) Short-term culture and gammaH2AX flow cytometry determine differences in individual radiosensitivity in human peripheral $\mathrm{T}$ lymphocytes. Envir Mol Mut 48: 38-47.

Hertveld TK, Philippé J, Thierens H, Cornelissen M, Vral A, De Ridder L (1997) Flow cytometry as a quantitative and sensitive methods to evaluate low dose radiation induced apoptosis in vitro in human peripheral blood lymphocytes. Int J Radiat Biol 71: 429-433.

Jones GG, Reaper PM, Pettitt AR, Sherrington PD (2004) The ATR-p53 pathway is suppressed in noncycling normal and malignant lymphocytes. Oncogene 23: 1911-1921.

Ju R, Muller MT (2003) Histone deacetylase inhibitors activate p21(WAF1) expression via ATM Cancer Res 63: 2891-2897.

Kang J, Ferguson D, Song H, Bassing C, Eckersdorff M, Alt FW, Xu Y (2005) Functional interaction of H2AX, NBS1, and p53 in ATM-dependent DNA damage responses and tumor suppression. Mol Cell Biol 25: 661-670.

Kapoor M, Lozano G (1998) Functional activation of p53 via phosphorylation following DNA damage by UV but not $\gamma$-radiation. Proc Natl Acad Sci USA 95: 2834-2837. 
Lakin ND, Jackson SP (1999) Regulation of p53 in response to DNA damage. Oncogene 18: 7644-7655.

Lineweaver H, Burk D (1934) The determination of enzyme dissociation constants. I Am Chem Soc 56: 658-666.

Mukherjee B, Kessinger C , Kobayashi J, Chen BP, Chen DJ, Chatterjee A, Burma S (2006) DNA-PK phosphorylates histone H2A.X during apoptotic DNA fragmentation in mammalian cells. DNA Repair (Amst) 5: 575-590.

Ocker M, Schneider-Stock R (2007) Histone deacetylase inhibitors: signalling towards $\mathrm{p} 21^{\mathrm{cip} 1 / \text { waf1 }}$. Int J Biochem Cell Biol 39: 1367-1374.

Pettitt AR, Sherrington PD, Stewart G, Cawley JC, Malcolm A, Taylor R, Stankovic T (2001) p53 dysfunction in Bcell chronic lymphocytic leukemia: inactivation of ATM as an alternative to TP53 mutation. Blood 98: 814-822.

Philippé J, Louagie H, Thierens H, Vral A, Cornelissen M, De Ridder L (1997) Quantification of apoptosis in lymphocyte subsets and effect of apoptosis on apparent expression of membrane antigens. Cytometry 29: 242-249.

Porcedda P, Turinetto V, Lantelme E, Fontanella E, Chrzanowska K, Ragona R, De Marchi M, Delia D, Giachino C (2006) Impaired elimination of DNA double-strand break-containing lymphocytes in ataxia telangiectasia and Nijmegen breakage syndrome. DNA Repair 5: 904-913.

Rezáčová M, Tichý A, Vávrová J, Vokurková D, Lukáová E (2008) Is defect in phosphorylation of Nbs1 responsible for high radiosensitivity of T-lymphocyte leukemia cells MOLT-4? Leuk Res 32: 1259-1267.

Rogakou EP, Pilch DR, Orr AH, Ivanova VS, Bonner WM (1998) DNA double-stranded breaks induce histone H2AX phosphorylation on serine-139. J Biol Chem 273: 5858-5868.

Schultz LB, Chehab NH, Malikzay A, Halazonetis TD (2000) p53 binding protein (53BP1) is an early participant in cellular response to DNA double-strand breaks. J Cell Biol 151: 1381-1390.

Shieh SY, Ikeda M, Taya Y, Prives C (1997) DNA damageinduced phosphorylation of p53 alleviates inhibition by MDM2. Cell 91: 325-334.

Siliciano JD, Canman CE, Taya Y, Sakaguchi K, Appella E, Kastan MB (1997) DNA damage induces phosphoryla- tion of the amino terminus of p53. Genes Dev 11: 34713481.

Stiff T, Driscoll MO, Rief N, Iwabuchi K, Lobrich M, Jeggo PA (2004) ATM and DNA-PK function redundantly to phosphorylate H2A.X after exposure to ionizing radiation. Cancer Res 64: 2390-2396.

Szkanderová S, Vávrová J, Řezáčová M, Vokurková D, Pavlová Š, Šmardová J, Stulík J (2003) Gamma irradiation results in phosphorylation of p53 at serine-392 in human T-lymphocyte leukaemia cell line MOLT-4. Fol Biol 49: 191-196.

Szkanderová S, Vávrová J, Hernychová L, Neubauerová V, Lenčo J, Stulík J (2005) Proteome alterations in gammairradiated human T-lymphocyte leukemia cells. Radiat Res 163: 307-315.

Tichý A, Záškodová D, Řezáčová M, Vávrová J, Vokurková D, Pejchal J, Vilasová Z, Cerman J, Osterreicher J (2007) Gamma-radiation-induced ATM-dependent signaling in human T-lymphocyte leukemic cells, MOLT4. Acta Biochem Polon 54: 281-287.

Vávrová J, Mareková M, Vokurková D, Psutka J (2004) Cell cycle alteration and response to low-dose-rate gamma radiation in leukemic cell lines. Physiol Res 53: 335-342.

Voelkerding KV, Steffen DW, Zaidi SHE, Malter JS (1995) Post-transcriptional regulation of the p53 tumor suppressor gene during growth-induction of human peripheral blood mononuclear cells. Oncogene 10: 515521.

Vokurková D, Šinkora J, Vávrová J, Řezáčová M, Knížek J, Osterreicher J (2006) CD8+ natural killer cells have a potential of a sensitive and reliable biodosimetric marker in vitro. Physiol Res 55: 689-698.

Weinberg RA (2007) The biology of cancer. Garland Science, Taylor and Francis Group, LLC. New York, 795 p.

Zhao Y, Lu S, Wu L, Chai G, Wang H, Chen Y, Sun J, Yu Y, Zhou W, Zheng Q, Wu M, Otterson GA, Zhu WG (2006) Acetylation of p53 at lysine 373/382 by the histone deacetylase inhibitor depsipeptide induces expression of p21 Waf1/Cip1. Mol Cell Biol 26: 2782-2790. 